\title{
Extração e caracterização de carboidratos presentes no alho (Allium sativum L.): proposta de metodologia alternativa
}

\author{
Extraction and characterization of carbohydrates present in the garlic (Allium sativum L.): \\ proposal of alternative methods
}

\section{Nicole DALONSO${ }^{2}$, Estér IGNOWSKI², Claudia Mariane Adão MONTEIRO², Michael GELSLEICHTER ${ }^{2}$, Theodoro Marcel WAGNER ${ }^{2}$, Marcia Luciane Lange SILVEIRA ${ }^{1 *}$, Denise Abatti Kasper SILVA ${ }^{3}$}

\section{Resumo}

O alho é um alimento funcional que contém inulina, um polissacarídeo de reserva, que auxilia no controle das bactérias patogênicas e putrefativas existentes no intestino. O presente trabalho teve por objetivo avaliar uma metodologia simples de extração de carboidratos do alho, qualificar e quantificar a composição desse extrato empregando a cromatografia líquida de alta eficiência e a espectroscopia na região do infravermelho utilizando para isso um padrão de inulina. Os bulbos de alho foram submetidos à extração aquosa a quente por 4 horas; posteriormente o líquido resultante foi separado e a ele foram adicionados $300 \mathrm{~mL}$ de acetona. $\mathrm{O}$ extrato isolado foi avaliado quanto aos seus produtos de hidrólise alcalina e os resultados indicaram a presença de um oligossacarídeo como o observado para a inulina padrão. As

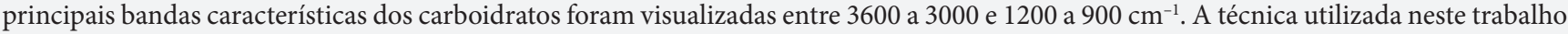
pode ser utilizada para extração da inulina, pois agrega valor a produtos naturais, gerando alternativas do ponto de vista econômico.

Palavras-chave: extrato de alho; carboidratos; inulina; cromatografia; espectroscopia de infravermelho.

\begin{abstract}
Garlic is a functional food that contains inulin, a reserve polysaccharide, which helps in the control of pathogenic and putrefactive bacterial present in the intestine. The aim of this work was to evaluate a simple method for the extraction of garlic carbohydrates and to qualify and quantify the composition of the extract using high performance liquid chromatography and infrared spectroscopy using the standard inulin. The bulbs of garlic were submitted to a four-hour water extraction and the remaining liquid was separated by centrifugation and added to $300 \mathrm{~mL}$ of acetone. The isolated extract was evaluated in relation to its products of alkaline hydrolysis and the results indicate the presence of an oligosaccharide as observed for the standard inulin. The main characteristic bands of carbohydrate were identified in the range of $3600-3000 \mathrm{~cm}^{-1}$ and $1200-900 \mathrm{~cm}^{-1}$. The technique used in this work can be applied for the inulin extraction since it aggregates value to the natural products generating alternatives from the economical point of view.

Keywords: garlic extract; carbohydrates; inulin; chromatography; infrared spectroscopy.
\end{abstract}

\section{Introdução}

O alho (Allium sativum L.) é um alimento funcional rico em alicina que possui ação antiviral, antifúngica e antibiótica, tem considerável teor de selênio agindo como antioxidante e aliina que apresenta ação hipotensora e hipoglicemiante. Alguns compostos sulfurados presentes no alho possuem atividade vasodilatadora e hipocolesterolemiante, reduzindo o risco de doenças cardiovasculares. As demais substâncias encontradas no alho possuem atividade imunoestimulatória e antineoplásica (CORZO-MARTÍNEZ; CORZO; VILLAMIEL, 2007; MARCHIORI, 2007).

O alho possui também inulina, um polissacarídeo de reserva que tem importantes propriedades funcionais, classificando-se como um fruto-oligossacarídeo de ligações $\beta$ - 2,1 entre as frutoses da cadeia principal, contendo uma glucose terminal e cadeias laterais de frutose ligadas $\beta-2,6$ (BAUMGARTNER et al., 2000). Esta molécula estimula os componentes do sistema imune, ajuda na absorção de cálcio, favorece a síntese da vitamina $B$ e diminui parâmetros lipídicos (BALCÁZAR-MUÑOZ; MARTÍNEZABUNDIS; GONZÁLEZ-ORTIZ, 2003).

Segundo Roberfroid (2005), a inulina age como fibra alimentar e prebiótico, melhorando a flora intestinal, resultando em alívio de constipação, melhoria da composição de lipídios do sangue e eliminação da produção de substâncias putrefativas no trato intestinal.

Este polissacarídeo resiste à lise no sistema digestivo humano, o que favorece seu emprego para produtos dietéticos. Ao alcançar o cólon, sofre degradação por Bifidobactérias,

Recebido para publicação em 17/12/2007

Aceito para publicação em 5/1/2009 (003109)

${ }^{1}$ Farmácia e Gastronomia, Universidade da Região de Joinville - Univille, CEP 89201-972, Joinville - SC, Brasil, E-mail: cesmar@terra.com.br

${ }^{2}$ Departamento de Química Industrial, Universidade da Região de Joinville - Univille, CEP 89201-972, Joinville - SC, Brasil

${ }^{3}$ Departamento de Farmácia e Engenharia Ambiental, Universidade da Região de Joinville - Univille, CEP 89201-972, Joinville - SC, Brasil

${ }^{*}$ A quem a correspondência deve ser enviada 
o que estimula o crescimento bacteriano no cólon, inibe o crescimento de bactérias patogênicas e putrefativas, reduz a formação de produtos tóxicos da fermentação e age na prevenção do câncer de cólon (KOLIDA; GIBSON, 2007; HAULY; MOSCATTO, 2002).

Algumas propriedades reológicas da inulina permitem sua aplicação no setor de alimentos com baixo teor de gorduras. Esta característica se deve à viscosidade deste polissacarídeo em solução aquosa, agindo como um modificador de textura na produção de alimentos (BRENNAN; TUDORICA, 2007).

Devido à grande concentração de inulina na raiz da chicória (15-20\%) ou tubérculos de alcachofra (16-20\%), métodos de extração deste prebiótico nestes vegetais são amplamente abordados na literatura (LEITE et al., 2004; LÓPEZ-MOLINA et al., 2005). Para o alho existem poucas referências quanto à metodologia de extração, por esta razão a necessidade de explorar este tema, visto que, além da inulina, o alho contém diversos nutrientes com propriedades terapêuticas.

O cultivo do alho envolve várias etapas no plantio e, após a colheita, os bulbos passam por processos de beneficiamento, em que há cura para remoção do excesso de água, corte das raízes e hastes dos bulbos, classificação, limpeza e embalagem. Nestas etapas ocorrem perdas que podem diminuir o lucro desta importante atividade (LUCINI, 2005).

Verificando a importância dos alimentos funcionais e prebióticos no equilíbrio e bom funcionamento do trato intestinal, almejando agregar valor a produtos de origem vegetal, este trabalho teve por objetivo avaliar uma metodologia simples de extração de carboidratos do alho, qualificar e quantificar a composição desse extrato empregando a cromatografia líquida de alta eficiência e a espectroscopia na região do infravermelho utilizando para isso um padrão de inulina.

\section{Material e métodos}

\subsection{Extração aquosa dos bulbos de alho}

Após descasque, 165,6 $\mathrm{g}$ de bulbos de alho frescos, obtidos de um comércio local, foram triturados, a ele adicionados $300 \mathrm{~mL}$ de água destilada a $100{ }^{\circ} \mathrm{C}$, mantidos em agitação (500 rpm) com fervura, por 4 horas e, posteriormente, o extrato foi separado do resíduo através de filtração simples. Ao extrato adicionaram-se $300 \mathrm{~mL}$ de acetona, precipitando imediatamente o polissacarídeo. Este extrato foi centrifugado a $5000 \mathrm{rpm}$ por 5 minutos (Sigma $4 \mathrm{~K}, \mathrm{n}^{\circ}$ rotor 12254 ) e o precipitado obtido foi liofilizado (Terroni Fauvel - LT 1000/8).

\subsection{Preparação da amostra e análise em espectroscopia de infravermelho}

Aproximadamente $1 \mathrm{mg}$ da amostra liofilizada foi adicionada ao cloreto de potássio na proporção 1:7 (amostra:KCl) e macerada até a obtenção de uma mistura homogênea. A seguir foram preparadas pastilhas em prensa hidráulica, aplicando-se uma força de 20 toneladas, que foram submetidas à análise por infravermelho em equipamento Perkin Elmer 1420. O mesmo procedimento foi adotado para o controle (inulina padrão analítico 98\% - Fluka).

\subsection{Preparação da amostra para análise em cromatografia líquida de alta eficiência}

Ao extrato de alho e ao padrão de inulina (18 mg de cada) foi adicionado $1 \mathrm{~mL}$ de hidróxido de amônio $50 \%$ para promover a hidrólise alcalina do polissacarídeo. Com o auxílio de um banho de água a $90^{\circ} \mathrm{C}$, as duas amostras foram solubilizadas e evaporadas até a secura (com vapor de água a $100^{\circ} \mathrm{C}$ ). Foram adicionados $5 \mathrm{~mL}$ de água destilada ao resíduo, que foi filtrado (Milex Sigma $13 \mathrm{~mm}, 0,5 \mu \mathrm{m}$ ), e injetado em cromatógrafo Merck-Hitachi com detector de índice de refração, em coluna Knauber $\mathrm{Pb}$ mantida em forno a $80^{\circ} \mathrm{C}$, tendo água MiliQ como fase móvel $(0,5 \mathrm{~mL} /$ minuto).

\section{Resultados e discussão}

\subsection{Obtenção do extrato de alho}

Imediatamente após a adição da acetona, observou-se a formação de um precipitado branco que foi, posteriormente, separado por centrifugação e liofilizado, resultando em 3,438 g ( $5 \%$ em relação à massa seca de alho).

Segundo Oliveira et al. (2004), num estudo para otimização da extração de inulina da chicória, mantendo-se o tempo de extração de todos os ensaios em 1 hora, foi verificado que o rendimento aumenta numa dependência linear com o aumento da temperatura do banho, da relação água : raiz e da interação temperatura/relação água : raiz. Diminuindo numa dependência quadrática com o aumento da temperatura do banho e da relação água:raiz.

No presente trabalho, optou-se por utilizar temperatura mais alta do banho $\left(100^{\circ} \mathrm{C}\right)$, devido ao aumento da difusividade da inulina em água quente, auxiliando na solubilização, um tempo maior de extração (4 horas) e relação água/bulbo seco de 4,5 .

Leite et al. (2004) realizaram a extração da inulina da chicória por difusão em água quente, tendo as raízes sido trituradas e a elas adicionada água na proporção 1:2 (raízes: água). A mistura foi mantida numa temperatura média de $80 \pm 2{ }^{\circ} \mathrm{C}$ por 1 hora com constante agitação. A precipitação da inulina foi realizada pela redução da temperatura $\left(-24^{\circ} \mathrm{C}\right)$ e os melhores resultados sugerem um processo de centrifugação numa velocidade de $6.000 \mathrm{rpm}$ por 15 minutos.

A extração poderia ser conduzida por repetidas fervuras do bulbo do alho, caso o objetivo fosse aumentar o rendimento. Porém, extrações sequenciais demandam tempo e, além de exigirem grandes quantidades de solventes orgânicos, também geram gastos energéticos, sendo de difícil emprego no setor industrial. $\mathrm{O}$ alho residual, após extração em uma única etapa de fervura por 4 horas, pode ainda ser empregado na indústria de alimentos, compondo aroma e sabor característicos em temperos e pastas para fins especiais. 
O etanol também é uma boa alternativa no emprego como agentes precipitantes, visto que é de uso comum e baixo custo de aquisição. Mas a acetona é mais específica na precipitação de polissacarídeos (MOERMAN; VAN LEEUWEN; DELCOUR et al., 2004), pois remove a água de solvatação destas biomoléculas com mais eficiência que o etanol, promovendo desidratação e consequente precipitação. Destaca-se ainda que a acetona possui um ponto de ebulição inferior $\left(56,5^{\circ} \mathrm{C}\right)$ ao do etanol $\left(78,5^{\circ} \mathrm{C}\right)$ e, desta forma, pode ser mais facilmente recuperada por destilação.

A maioria dos trabalhos encontrados na literatura para extração de inulina inclui precipitação deste polissacarídeo com abaixamento da temperatura ou concentração do extrato aquoso. A adição de solventes orgânicos não somente diminui a solubilidade dos polissacarídeos em água, precipitando-os, mas também já é uma forma de purificação destes biopolímeros, visto que no sobrenadante permanecem os compostos de baixa massa molecular, pigmentos e sais. Neste trabalho optou-se por usar a acetona ao invés de etanol como agente precipitante, pois, segundo García-Ochoa et al., (2000) o dobro do volume de etanol é requerido para se ter o mesmo rendimento em polissacarídeos.

\subsection{Análise por infravermelho}

O espectro de infravermelho (Figura 1) comprova a estrutura de um polissacarídeo com ligação C-O-C, característica de carboidratos, entre 1200 e $900 \mathrm{~cm}^{-1}$, confirmando a ligação entre os monômeros formadores do polímero. Em 3600 e $3000 \mathrm{~cm}^{-1}$ observa-se a banda da ligação O-H existente nas estruturas dos monossacarídeos e a deformação angular da ligação aparece em $1639 \mathrm{~cm}^{-1}$. O estiramento assimétrico do grupamento $\mathrm{CH}_{2}$ é observado em 2900 a $2950 \mathrm{~cm}^{-1}$ (SILVERSTEIN et al., 2006). $\mathrm{O}$ espectro obtido neste trabalho foi comparado com a inulina 98\% de pureza e verificou-se certa similaridade entre ambos. Por se tratar de um extrato de alho bruto, os picos são menos definidos, mais arredondados e há sobreposição de algumas bandas devido a interferentes, como os demais compostos orgânicos presentes no extrato.

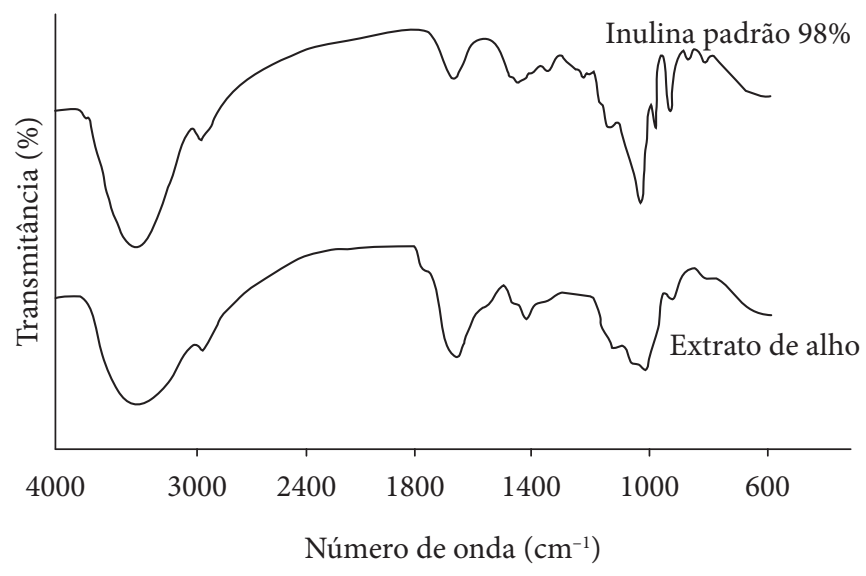

Figura 1. Espectro de infravermelho, modo transmitância, para o extrato isolado.
López-Molina et al. (2005) utilizaram técnicas de espectroscopia de infravermelho para caracterizar a inulina proveniente de extração aquosa da alcachofra. O autor empregou a cromatografia gasosa com detector de massa para identificar os monômeros da inulina como também às ligações $\beta-2,1$ entre as frutoses.

Cakié et al. (2002) estudaram complexos de ferro (III) com dextroses, pululanas e inulina. Os autores utilizaram a técnica de FTIR (infravermelho com transformada de Fourier) para verificar o deslocamento de certas bandas dos carboidratos após incorporação do ferro pelas matrizes.

\subsection{Análise por Cromatografia Líquida de Alta Eficiência (CLAE)}

A Tabela 1 apresenta os resultados da análise em CLAE com os respectivos tempos de retenção, substância encontrada, concentração e área percentual para o produto da hidrólise do extrato obtido.

A Figura 2 apresenta o cromatograma obtido a partir da hidrólise alcalina do extrato de alho (a) e da inulina hidrolisada em seu monômero (b).

Após hidrólise alcalina do extrato isolado houve a formação de um oligossacarídeo, com baixo tempo de retenção (9,20 minutos), fato este também verificado com a inulina padrão analítico, quando esta foi submetida às mesmas condições experimentais (Figura 2). Segundo De Leenheer (1996), a inulina nativa, extraída de raízes frescas, sempre contém glucose, frutose, sacarose e pequenos oligossacarídeos. Este fato foi verificado na presença de pequena quantidade de sacarose e frutose no extrato de alho (Figura 2a).

Com relação à massa fresca $(165,6 \mathrm{~g})$ de bulbos de alho empregados na extração, 66,24 g correspondem à matéria seca, no entanto o rendimento total de inulina foi aproximadamente $2,65 \%$. Já com relação à massa seca de extrato obtido $(3,438 \mathrm{~g})$, o rendimento em inulina foi de $51 \%$, sendo que os demais carboidratos representam $8,28 \%$ de frutose e apenas $1 \%$ de sacarose.

Oliveira et al. (2004) determinaram a quantidade de inulina através dos sólidos solúveis extraídos da chicória por difusão em água quente, utilizando um refratômetro de bancada. $\mathrm{O}$ rendimento foi de $0,91 \%$ quando em um dos pontos do planejamento experimental aplicaram-se $98^{\circ} \mathrm{C}$ e relação água/ massa seca de raiz de 8,5 .

Leite et al. (2004) observaram um rendimento de $40,8 \%$ de inulina para as raízes da chicória extraídas por difusão a quente, concentradas por evaporação e precipitadas por abaixamento da

Tabela 1. Tempos de retenção, substância encontrada, concentração e área percentual para o produto da hidrólise do extrato obtido.

\begin{tabular}{cccc}
\hline $\begin{array}{c}\text { Tempo de retenção } \\
(\mathrm{min})\end{array}$ & Substância & $\begin{array}{c}\text { Concentração } \\
\left(\mathrm{g} . \mathrm{L}^{-1}\right)\end{array}$ & $\begin{array}{c}\text { Área } \\
(\%)\end{array}$ \\
\hline 9,20 & Inulina & 1,75264 & 77,881 \\
13,05 & Sacarose & 0,0368230 & 1,79 \\
21,25 & Frutose & 0,284969 & 12,512 \\
\hline
\end{tabular}



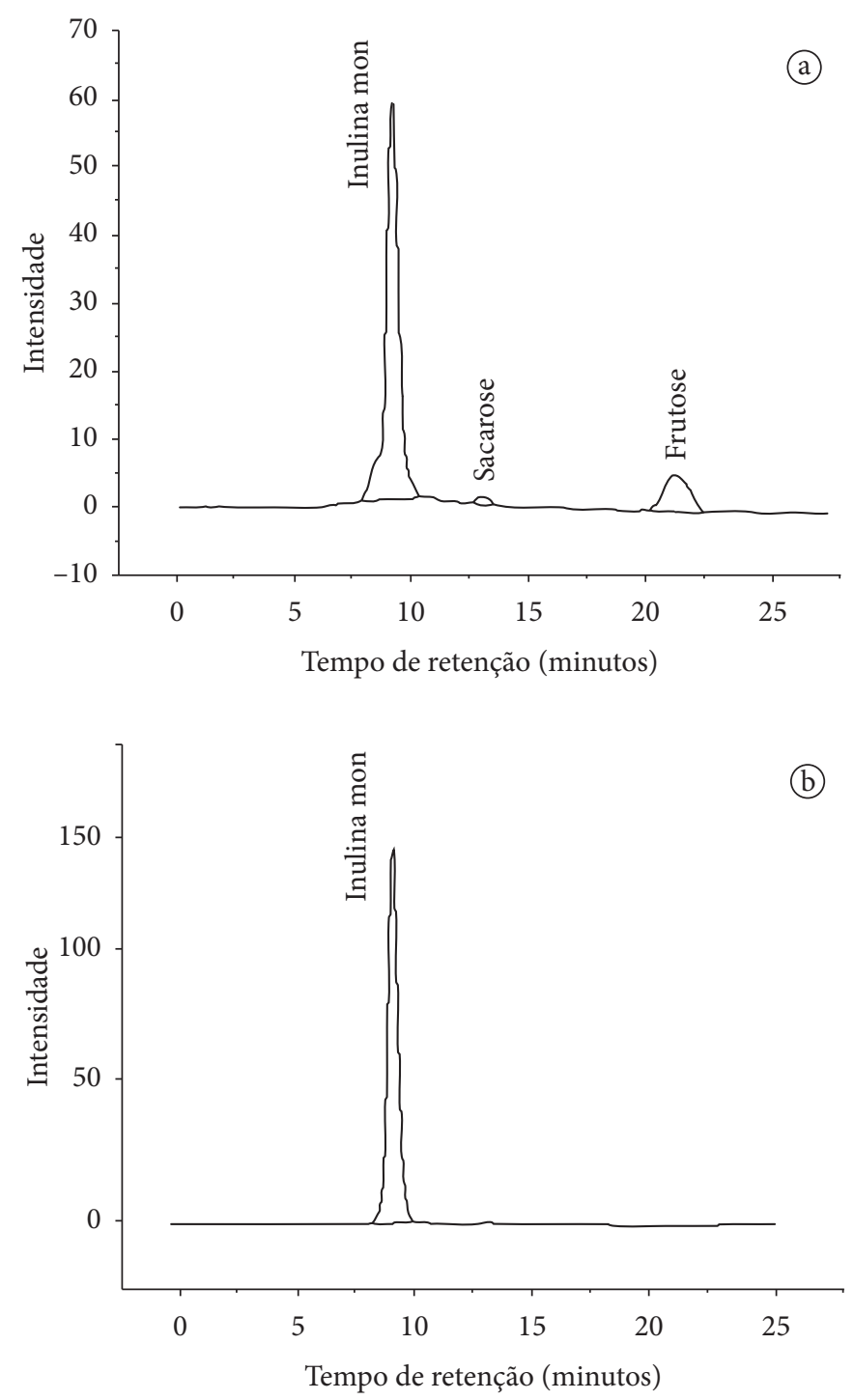

Figura 2. Cromatograma obtido a partir da hidrólise alcalina do extrato de alho (A) e da inulina hidrolisada padrão analítico em seu monômero (B).

temperatura. Porém o autor apenas analisou gravimetricamente, ou seja, poderiam estar presentes outros compostos oriundos do tubérculo.

Müller et al. (2006) estudaram os produtos de hidrólise da inulina, obtidos pela ação de endoinulinases produzidas por Paenibacillus sp. Os resultados obtidos mostraram que é possível, mesmo considerando a complexidade da mistura de oligômeros presentes após a hidrólise, proceder à sua quantificação por CLAE em coluna de troca iônica. O padrão de hidrólise, observado pela ação da endoinulinase sobre a inulina, indicou a produção de inulotriose como o principal oligômero.

\section{Conclusões}

A metodologia de extração de carboidratos apresentada neste trabalho mostrou-se eficaz, resultando num extrato composto por $51 \%$ de inulina, $8,28 \%$ de frutose e $1 \%$ de sacarose, ou seja, permitiu extrair diferentes sacarídeos, destacando-se como principal polissacarídeo a inulina. Por sua simplicidade, esta metodologia pode tornar-se uma alternativa importante como forma de agregar valor aos bulbos de alho e também aos bulbilhos que não se enquadram na classe para comercialização, gerando alternativas do ponto de vista econômico. $\mathrm{O}$ espectro de infravermelho e a hidrólise alcalina do extrato isolado apresentaram comportamentos similares ao padrão analítico da inulina. O desenvolvimento de novas técnicas de extração visa praticidade e eficiência, sendo necessárias análises químicas rápidas e seguras, tendo como bons alicerces a espectroscopia de infravermelho e a cromatografia líquida de alta eficiência.

\section{Referências bibliográficas}

BALCÁZAR-MUÑOZ, B. R.; MARTÍNEZ-ABUNDIS, E.; GONZÁLEZORTIZ, M. Efecto de la administración oral de inulina sobre el perfil de lípidos y la sensibilidad a la insulina en individuos com obesidad y dislipidemia. Revista Médica do Chile, v. 131, n. 6, 2003.

BAUMGARTNER, S. et al. Characterisation of the high-molecular weight fructan isolated from garlic (Allium sativum L.). Carbohydrate Research, v. 328, n. 2, p. 177-183, 2000.

BRENNAN, C. S.; TUDORICA, C. M. Carbohydrate-based fat replacers in the modification of the rheological, textural and sensory quality of yoghurt: comparative study of the utilisation of barley beta-glucan, guar gum and inulin. International Journal Food Science and Technology, v. 43, n. 5, p. 824-833, 2007.

CAKIÉ, M. D.; NIKOLIÉ, G. S.; ILIÉ, L. A. FTIR spectra of iron (III) complexes with dextran, pullulan and inulin oligomers. Bulletin of the Chemists and Technologists of Macedonia, v. 21, n. 2, p. 135-146, 2002.

CORZO-MARTÍNEZ, M.; CORZO, N.; VILLAMIEL, M. Biological properties of onions and garlic. Trends in Food Science \& Technology, v. 18, n. 12, p. 609-625, 2007.

DE LEENHEER, L. Production and use of inulin: industrial reality with a promising future. In: VANBEKKUM, H.; ROPER, H.; VARAGEN, F. (Ed.). Carbohydrates as organic raw materials. New York: VCH Publishing, 1996. v. 3, p. 67-92.

GARCÍA-OCHOA, F. et al. Xanthan gum: production, recovery, and properties. Biotechnology Advances, v. 18, n. 7, p. 549-579, 2000.

HAULY, M. C. O.; MOSCATTO, J. A. Inulin and oligofructosis: a review about functional properties, prebiotic effects and importance for food industry. Semina: Ciências Exatas e Tecnológica, v. 23, n. 1, p. 105-118, 2002.

KOLIDA, S.; GIBSON, G. R. Prebiotic Capacity of Inulin-Type Fructans. The Journal of Nutrition, v. 137, n. 11, p. 2503S-2506S, 2007.

LEITE, J. T. C. et al. Study of the inulin concentration by physical methods. In: INTERNATIONAL DRYING SYMPOSIUM, 14, 2004. Proceedings... São Paulo, 2004. v. B, p. 868-875.

LÓPEZ-MOLINA, D. et al. Molecular properties and prebiotic effect of inulin obtained from artichoke (Cynara scolymus L.). Phytochemistry, v. 66, n. 12, p. 1476-1484, 2005.

LUCINI, M. A. Cultura do Alho. In: Escritório local de Curitibanos Santa Catarina. Santa Catarina: Empresa de Pesquisa Agropecuária e Extensão Rural de Santa Catarina - EPAGRI, 2005. p. 1-9. Disponível em: <http://www.anapa.com.br/principal/images/ stories/documentos/Cultura_do_alho_no_sul.pdf>. Acesso em: Outubro 2008. 
MARCHIORI, V. F. Propriedades funcionais do alho (Allium sativum L.). Disponível em: <http://www.esalq.usp.br/ siesalq/pm/alho_revisado.pdf $>$. Acesso em: Outubro 2007.

MOERMAN, F. T.; Van LEEUWEN, M. B.; DELCOUR, J. A. Enrichment of higher molecular weight fractions in inulin. Journal of Agricultural and Food Chemistry, v. 52, n. 12, p. 3780-3783, 2004.

MÜLLER, J. M. et al. Caracterização de oligofrutoses produzidas por endo-inulinases de Paenibacillus sp. Boletim Centro de Pesquisa de Processamento de Alimentos, v. 24, n. 2, p. 363-374, 2006.
OLIVEIRA, R. A. et al. Otimização de extração de inulina de raízes de chicória. Revista Brasileira de Produtos Agroindustriais, v. 6, n. 2, p.131-140, 2004.

ROBERFROID, M. B. Inulin: origin, chemistry, biochemistry, and technological properties. In: Inulin-type fructans: functional foods ingredients. Boca Raton: CRC Press, 2005. Part II, p. 115-261.

SILVERSTEIN, R. M.; WEBSTER, F. X.; KIEMLE, D. J. Identificação espectrométrica de compostos orgânicos. 7 ed. Rio de Janeiro: LTC, 2006. 